ISSN 0001-6002/2003/45/2/43-44

Acta Médica Costarricense,(C2003

Colegio de Médicos y Cirujanos

\title{
Apéndice, apendicitis, apendicectomía
}

El apéndice vermiforme del ser humano es un pequeño elemento cuya inflamación lo coloca en la lista de órganos que los cirujanos tenemos que aprender a extirpar en nuestro ascenso hacia la especialización. Al empezar el internado o la residencia uno sueña con diagnosticar y con oír del residente mayor "...hágase esta apéndice”.

Pero también hemos oído que el apéndice vermiforme es un órgano que se encuentra en involución, lo que implicaría que eventualmente las futuras generaciones de seres humanos ya no lo tendrían.

Sin embargo, en realidad las cosas no son tan claras. Los seres invertebrados no tienen apéndice, tampoco muchos vertebrados como los peces, los reptiles y los pájaros y uno podría pensar que ello se deba a que sus dietas son muy diferentes a la nuestra. Si vemos en los mamíferos, que dicho sea de paso aparecieron hace 200 millones de años, los perros, los gatos, los caballos y los rumiantes tampoco la tienen, como si evolutivamente ya fuesen entonces seres mas avanzados que nosotros ${ }^{1}$. Pero finalmente otros mamíferos dentro de sus propias especies, pueden tenerla o no, tales como los marsupiales o los roedores.

El concepto de la "involución del apéndice" es basado en propuestas evolucionistas del mismo Darwin, quien lo consideró como un órgano rudimentario o como un vestigio de órgano, ya que seres herbívoros de otras especies poseen un ciego distal y un apéndice más desarrollado que el nuestro y cuya función, el pensó, era similar ${ }^{2}$. El ciego provee más espacio y bacterias para la digestión de los vegetales.

Es difícil determinar si hubo o no apéndice y que función cumplía en nuestros antecesores ya que en los restos disponibles no es posible encontrar sus rastros, por haber sido todo digerido por la acción bacteriana y si la hubieran tenido, en realidad, no se aclararía mucho porque mil o mas años son períodos cortos en términos paleontológicos.

Todo lo anterior, en realidad, cuestiona la propuesta de la "involución" y hoy, autores muy serios creen que el apéndice constituye más bien una porción altamente especializada del tracto gastrointestinal, formando parte de los llamados órganos GALT (gut associated lymphoid tissue) ${ }^{1,3,4}$. Los linfocitos empiezan a poblar el apéndice de la $10^{\mathrm{a}}$ a la $20^{\mathrm{a}}$ semana de vida fetal y luego durante las primeras semanas de vida se agrupan en folículos linfoides, hecho que coincide con la colonización del ciego por las bacterias ${ }^{1}$. Los folículos continúan aumentando en número y de $\operatorname{los} 12$ a los 20 años se llega a un máximo de unos 200 y de allí en adelante su número empieza a disminuir, habiendo unos 100 a los 30 años para ir luego desapareciendo durante el curso de la vida ${ }^{4}$.

El tejido linfoide apendicular esta involucrado en la producción de anticuerpos de 2 tipos, $\operatorname{los} \operatorname{Ig}$ A que están en la superficie de la mucosa recubriéndola como si fuera una capa protectora e IgM o IgG que son drenados a la sangre. Algunos creen que su función es separar el yeyuno mucho más limpio y sus fluidos del ciego, órgano lleno de bacterias y heces. En los años 60 estudios retrospectivos de autopsia sugirieron una mayor incidencia de cáncer de colon en apendicectomizados, pero esta relación no pudo ser corroborado en estudios prospectivos realizados posteriormente ${ }^{3}$. Hoy sabemos que la remoción del apéndice no trae consecuencias detectables y que es un órgano dispensable.

En general se acepta que la obstrucción del lumen apendicular es el factor desencadenante de la apendicitis aguda y como ocurre más en la gente joven, se implica en su patogenia el mayor contenido de tejido linfático en ellos, aunque también se asocia con la presencia de fecalitos y otros autores la relacionan con una dieta baja en fibra vegetal como ocurre en ciertos grupos étnicos ${ }^{5}$.

Durante la primera mitad de siglo XIX fueron presentados en las diferentes sociedades quirúrgicas europeas y reportados en las publicaciones pertinentes, casos floridos de apendicitis, con o sin estudios necrópsicos. Fitz, patólogo en Harvard, en 1886 estudió extensamente esta entidad y trató de convencer a sus colegas de que el apéndice y no el ciego, era la causa de la mayoría de las inflamaciones de la fosa iliaca derecha y dio las razones para ello, acuñó el termino, describió la clínica y definió claramente el tratamiento de la apendicitis aguda ${ }^{4,6}$.

En el presente número de Acta Médica, Rodríguez Herrera presenta un estudio sobre 120 niños apendicectomizados por apendicitis aguda, en el Hospital de San Carlos durante 32 meses a partir de enero de $1999^{7}$. Solo 14 pacientes $(11.6 \%)$, no tenían apendicitis demostrable histopatológicamente $(8 \mathrm{~F} / 6 \mathrm{M})$. Este dato es enteramente aceptable y se encuentra respaldado por la bibliografía del mismo artículo y por otros autores que recomiendan que la tasa de apéndices sanos resecados varíe del 10 al $15 \%{ }^{4}$. Si ese número es muy bajo se presume que el cirujano espera estar ya muy seguro del diagnóstico antes de intervenir y con ello al dar tiempo, esta arriesgando la posibilidad de una perforación y por otro lado si él numero de "apéndices sanas" removidas es alto, se 
supone que el cirujano esta operando muy pronto en el curso de la presentación del enfermo y posiblemente algunos no necesitaban ser intervenidos por tener otras causas de dolor abdominal.

No hubo mortalidad en esta serie de San Carlos y aunque las complicaciones no se mencionan, los resultados son muy buenos, puesto que en la literatura se cita una mortalidad de alrededor del $2 \%$ en niños y un poquito más en adultos ${ }^{6}$. En un estudio ya lejano sobre peritonitis aguda de diversas causas en 76 adultos, 2 de 6 con apendicitis perforada fallecieron y a medida que aumenta la edad de los pacientes así aumenta la mortalidad ${ }^{7}$.

El autor llama la atención sobre el hecho de que un porcentaje considerable de pacientes de ese grupo, habían sido tratados antes mediante una combinación de medicamentos o maniobras empíricas, que retrasaron la resolución adecuada del problema, con lo cual se aumentó la morbilidad de la enfermedad.

Él diagnostico de apendicitis aguda siempre ha sido un dilema para los médicos sobre todo en los extremos de la vida. Temprano durante mi propio entrenamiento fui confrontado con 2 pacientes que me enseñaron mucho, uno fue un niño de 8 años, con un cuadro de dolor en la fosa iliaca derecha y vómitos y una masa mal definida en esa área, que terminó siendo un hematoma del psoas en un paciente hemofílico, y el otro un niño post transplante renal recibiendo esteroides, con distensión abdominal y nauseas, sin leucocitosis ni fiebre y que tenía una peritonitis aguda difusa secundaria a una apendicitis perforada y cuyo postoper atorio fue tormentoso.

A raíz de ellos hice una búsqueda bibliográfica de métodos diagnósticos y encontré varios exámenes sobre todo en la literatura rusa que daban claramente en el clavo. Estudiamos el que parecía más verosímil, la "determinación del ácido siálico sérico” en un grupo de pacientes con dolor abdominal agudo de diversas causas (quirúrgicas o no) y también en un grupo control de estudiantes de medicina sanos, pero para nuestra decepción este examen no demostró tener ningún valor diagnóstico o pronóstico en ninguno de los individuos 9 . A la fecha ningún examen de sangre tiene valor especifico en el diagnóstico de esta entidad.

Desde el punto de vista imagenológico, la radiografía simple de abdomen fue siempre parte del armamentario diagnóstico y en la década de los 70 se agregó la tomografía, hoy la primera no se considera de valor y la segunda es impráctica por la falta de aparatos y por su costo. El ultrasonido abdominal y especialmente el realizado con compresión graduada se considera un método diagnostico de alta sensibilidad y especificidad ${ }^{10}$. Alvarado en 1986 propuso un índice (suma de 10 puntos) basado en síntomas y signos y en el diferencial del leucograma, pero este "score" luego se recomendó mas bien para definir cuales pacientes debían ser estudiados ultrasonográficamente ${ }^{10} \mathrm{y}$ la literatura hoy lo recomienda firmemente sobre todo en mujeres ${ }^{11}$.

\section{AMC,Abril-Junio 2003, vol 45 (2)}

En nuestro medio, en que no hay abundancia de equipos de ultrasonido ni de especialistas el diagnóstico de apendicitis esta basado en la clínica. El arte del interrogatorio y del examen físico así como la observación "armada"ejercitados concienzudamente dan buenos resultados ${ }^{11}$.

En cuanto al tratamiento, con la llegada de la laparoscopía ha ido habiendo en el mundo un giro hacia la apendicectomía laparoscópica. Pero aunque el paciente así tratado, tiene menos dolor y una estancia intra-hospitalaria un poco más corta, el costo de la intervención hoy es mayor y en pacientes con apendicitis perforadas la incidencia de abscesos intra-abdominales es 3 veces más alta que en pacientes con apendicectomía abierta ${ }^{11,12}$. Sin embargo al irse familiarizando los cirujanos con las técnicas de laparoscopía y al adquirir los hospitales en que trabajamos estos equipos, los abordajes cambiaran y la laparoscopía será también utilizada como método diagnóstico y terapéutico de acuerdo con el perfil del paciente.

\section{Dr. Carlos Salazar Vargas FACS/FCCP/FAHA}

\section{Bibliografía}

1. Glover JW. The human vermiform appendix- A general surgeon's reflections. Technical Journal (Creation Ex Nihilo) 1988; 3:31-38.

2. Menton DN. The human tail and other tales of evolution. Missouri Association for Creation Inc. 1997

3. Schwartz SI. Appendix. En Schwartz, Shires y Spencer (Eds.) Principles of Surgery. New York McGraw-Hill. 1994 1307-1318.

4. Sabiston D. Appendicitis. En Sabiston (Editor).Textbook of Surgery. Philadelphia. WB Saunders.1997 págs. 964-970.

5. Black J. Acute appendicitis in J apanese soldiers in Burma: support for the "fibre" theory. Gut 2002; 51:297.

6. Da Costa HC. Modern Surgery. Philadelphia. WB. Saunders 1918. Págs. 1001-1017.

7. Rodriguez G. Análisis de apendicetomías en menores de 13 anos. Acta Med Cost 2003

8. Ger R., Salazar C., Stratford F. Prognostic factors in generalised peritonitis. J R Coll Surg (Edinb) 1976; 21:173-176.

9. Salazar C., Weinberg G.,Rettura G., Weil P. La determinación del ácido siálico sérico en el diagnostico de apendicitis aguda. Laboratorio (Granada) 1980; 70(417): 197-204.

10. Douglas CD., Macpherson NE., Davidson PM., Gani JS. Randomised controlled trial of ultrasonography in diagnosis of acute appendicitis, incorporating the Alvarado score. BMJ 2000; 321:919-922.

11. Benjamin IS., Patel AG. Managing acute appendicitis. BMJ 2002; 325: 505-506.

12. Kurtz RJ., Heiman TM. Comparison of open and laparoscopic treatment of acute appendicitis. Am J Surg 2001; 182:211-214. 